\title{
FUZZY TRANSSHIPMENT PROBLEM WITH TRANSIT POINTS
}

\author{
R. Baskaran ${ }^{1}$, K.M. Dharmalingam ${ }^{2}$, S.N. Mohamed Assarudeen ${ }^{3 \S}$ \\ ${ }^{1}$ Department of Mathematics \\ Government Arts College \\ Melur, Madurai Dist, INDIA \\ ${ }^{2}$ Department of Mathematics \\ The Madura College \\ Madurai, INDIA \\ ${ }^{3}$ Department of Mathematics \\ Islamiah College \\ Vaniyambadi, INDIA
}

\begin{abstract}
In this fuzzy transshipment problem, origin, destination and transit points are considered. Here transit point is not the destination it is just like port / storage house / airport / refineries etc., and then the transit point has no demands. Then the transshipment problem is converted to transportation problem and solves the problem using fuzzy cost deviation algorithm.
\end{abstract}

AMS Subject Classification: $03 \mathrm{E} 72$

Key Words: fuzzy transportation problem, fuzzy transshipment problem, fuzzy cost deviation algorithm

\section{Introduction}

Orden [5] has extended transportation problem to include the case when trans-

Received: October 7, 2015

Published: May 9, 2016

${ }^{\S}$ Correspondence author (c) 2016 Academic Publications, Ltd.

url: www.acadpubl.eu 
shipment is also allowed. A transportation problem allows only shipments that go directly from a supply point to a demand point. In many situations, shipments are allowed between supply points or between demand points. Sometimes there may also be points (called transshipment points) through which goods can be transshipped on their journey from a supply point to a demand point. Shipping problems with any or all of these characteristics are transshipment problems. Fortunately, the optimal solution to a transshipment problem can be found by solving a transportation problem.

In what follows, we define a supply point to be a point that can send goods to another point but cannot receive goods from any other point. Similarly, a demand point is a point that can receive goods from other points but cannot send goods to any other point. A transshipment point is a point that can both receive goods from other points and send goods to other points. The following example illustrates these definitions (" - " indicates that a shipment is impossible).

The concept of fuzzy set was first introduced and investigated by Zadeh [9] and fuzzy numbers and arithmetic operations with these numbers introduced by Bellman \& Zadeh and Kaufmann in [2]. In [3] Nagoor Gani et al. solving transportation problem using fuzzy number and in [4] Nagoor Gani et al solved the transshipment problem in fuzzy environment. The paper organized as follows: Section 2 deals with basic definitions and formulation of the fuzzy transshipment problem. Section 3 deals with the procedure of Fuzzy Transshipment Model with Transit point. Section 4 deals with procedure for solving fuzzy transportation problem using fuzzy cost deviation algorithm and in section 5 numerical examples is illustrated.

\section{Preliminaries:}

Definition 1. A fuzzy set $\tilde{A}$ is defined by

$$
\tilde{A}=\left\{\left(x, \mu_{A}(x)\right): x \in A, \mu_{A}(x) \in[0,1]\right\} .
$$

In the pair $\left(x, \mu_{A}(x)\right)$, the first element $\mathrm{x}$ belong to the classical set $\mathrm{A}$, the second element $\mu_{A}(x)$, belong to the interval $[0,1]$, called Membership function.

Definition 2. A fuzzy set $\tilde{A}$ on $\mathrm{R}$ must possess at least the following three properties to qualify as a fuzzy number,

- $\tilde{A}$ must be a normal fuzzy set;

- $\alpha \tilde{A}$ must be closed interval for every $\alpha \in[0,1]$ 
- the support of $\tilde{A},{ }^{\circ}+\tilde{A}$, must be bounded.

Definition 3. It is a fuzzy number represented with three points as follows: $\tilde{A}=\left(a_{1}, a_{2}, a_{3}\right)$. This representation is interpreted as membership functions and holds the following conditions

- $a_{1}$ to $a_{2}$ is increasing function.

- $a_{2}$ to $a_{3}$ is decreasing function.

- $a_{1} \leq a_{2} \leq a_{3}$.

Definition 4. The following are the Operations of Triangular Fuzzy Numberthat can be performed on triangular fuzzy numbers: Let $\tilde{A}=\left(a_{1}, a_{2}, a_{3}\right)$ and $\tilde{B}=\left(b_{1}, b_{2}, b_{3}\right)$ and

- Addition: $\tilde{A}+\tilde{B}=\left(a_{1}+b_{1}, a_{2}+b_{2}, a_{3}+b_{3}\right)$.

- Subtraction: $\tilde{A}-\tilde{B}=\left(a_{1}-b_{3}, a_{2}-b_{2}, a_{3}-b_{1}\right)$.

- Multiplication:

$$
\tilde{A} \tilde{B}=\left(\min \left(a_{1} b_{1}, a_{1} b_{3}, a_{3} b_{1}, a_{3} b_{3}\right), a_{2} b_{2}, \max \left(a_{1} b_{1}, a_{1} b_{3}, a_{3} b_{1}, a_{3} b_{3}\right)\right)
$$

Definition 5. The graded mean integration method is used to defuzzify the triangular fuzzy number. The representation of triangular fuzzy number is $\tilde{A}=\left(a_{1}, a_{2}, a_{3}\right)$ and its defuzzified value is obtained by

$$
A=\frac{\left(a_{1}+4 a_{2}+a_{3}\right)}{6}
$$

Definition 6. The a-level set of the fuzzy number $\tilde{a}$ and $\tilde{b}$ is defined as the ordinary set $L_{\alpha}(\tilde{a}, \tilde{b})$ for which the degree of their membership function exceeds the level $\alpha \in[0,1]$.

$$
L_{\alpha}(\tilde{a}, \tilde{b})=\left\{a, b \in R^{m} \mid \mu(\tilde{a})\left(a_{i}, b_{j}\right) \geq \alpha, i=1,2, m, j=1,2,, n\right\} .
$$




\section{Formulation of the General Fuzzy Transshipment Problem}

The fuzzy transportation problem assumes that direct routs exist from each source to each destination. However, there are situations in which units may be shipped from one source to another or to other destinations before reaching their final destinations. This is called a fuzzy transshipment problem. The purpose of transshipment the distinction between a source and destination is dropped so that a transportation problem with $m$ source and $n$ destinations gives rise to a transshipment problem with $m+n$ source and $m+n$ destinations. The basic feasible solution to such a problem will involve $[(m+n)+(m+n)-1]$ or $2 m+2 n-1$ basic variables and if we omit the variables appearing in the ( $\mathrm{m}$ $+\mathrm{n}$ ) diagonal cells, we are left with $m+n-1$ basic variables.

Thus the fuzzy transshipment problem may be written as:

Minimize

$$
\tilde{Z}=\sum_{i=1}^{m+n} \sum_{j=1, j \emptyset_{i}}^{m+n} \tilde{c}_{i j} \tilde{x}_{i j} .
$$

Subject to

$$
\begin{gathered}
\sum_{j=1, j \epsilon_{i}}^{m+n} \tilde{x}_{i j}-\sum_{j=1, j \epsilon_{i}}^{m+n} \tilde{x}_{j i}=a_{i}, \quad i=1,2,3, \cdots, m, \\
\sum_{i=1, i \epsilon_{j}}^{m+n} \tilde{x}_{i j}-\sum_{i=1, i \epsilon_{j}}^{m+n} \tilde{x}_{j i}=\tilde{b}_{j}, j=m+1, m+2, m+3, \cdots, m+n,
\end{gathered}
$$

where $\tilde{x}_{i j} \geq 0, i, j=1,2,3, \cdots, m+n, j \neq i$ and $\sum_{i=1}^{m} \tilde{a}_{i}=\sum_{j=1}^{m} \tilde{b}_{j}$ then the problem is balance otherwise unbalanced.

The above formulation is a fuzzy transshipment model, the transshipment model is reduced to transportation form as:

Minimize

$$
\tilde{Z}=\sum_{i=1}^{m+n} \sum_{j=1, j \epsilon_{i}}^{m+n} \tilde{c}_{i j} \tilde{x}_{i j} .
$$

Subject to: 


$$
\begin{array}{ll}
\sum_{j=1}^{m+n} \tilde{x}_{i j}=\tilde{a}_{i}+T, & i=1,2,3, \cdots, m \\
\sum_{j=1}^{m+n} \tilde{x}_{i j}=T, & i=m+1, m+2, m+3, \cdots, m+n \\
\sum_{i=1}^{m+n} \tilde{x}_{i j}=T, & j=1,2,3, \cdots, m \\
\sum_{i=1}^{m+n} \tilde{x}_{i j}=\tilde{b}_{i}+T, & j=m+1, m+2, m+3, \cdots, m+n
\end{array}
$$

where $\tilde{x}_{i j} \geq 0, i, j=1,2,3, \cdots, m+n, j \neq i$, the above mathematical model represents a standard balanced transportation problem with $(\mathrm{m}+\mathrm{n})$ origins and $(\mathrm{m}+\mathrm{n})$ destinations. T can be interpreted as a buffer stock at each origin and destination. Since we assume that any amount of goods can be transshipped at each point, $\mathrm{T}$ should be large enough to take care of all transshipments. It is clear that the volume of good a transshipped at any point cannot exceed the amount produced or received and hence we take $T=\sum_{i=1}^{m} \tilde{a}_{i}$ or $\sum_{j=1}^{m} \tilde{b}_{j}$.

\section{Fuzzy Transshipment Model with Transit Point}

In this model $m$ origin and $n$ destination and $p$ transit points are included. In this model the total number of origins is $m+p$ and the total number of destinations is $p+n$.

We now describe how the optimal solution to a transshipment problem can be found by solving a transportation problem. Given a transshipment problem, we create a balanced transportation problem by the following procedure (assume that total supply exceeds total demand):

Step 1 If necessary, add a dummy demand point (with a fuzzy supply of $(0,0,0)$ and a demand equal to the problem's excess supply) to balance the problem. Shipments to the dummy and from a point to itself will, of course, have a zero shipping cost. Let $\mathrm{T}$ total available supply.

Step 2 Construct a transportation tableau as follows: A row in the tableau will be needed for each supply point and transshipment point, and a column will be needed for each demand point and transshipment point. Each supply point will have a supply equal to its original supply, and each demand point will have a demand equal to its original demand.

Let $T=$ total available supply. Then each transshipment point will have a supply equal to (point's original supply) $+T$ and a demand equal to (point's 
original demand) $+T$. This ensures that any transshipment point that is a net supplier will have a net outflow equal to the point's original supply, and, similarly, a net demander will have a net inflow equal to the point's original demand. Although we don't know how much will be shipped through each transshipment point, we can be sure that the total amount will not exceed T. This explains why we add $\mathrm{T}$ to the supply and demand at each transshipment point. By adding the same amounts to the supply and demand, we ensure that the net outflow at each transshipment point will be correct, and we also maintain a balanced transportation tableau.

\section{Fuzzy Cost Deviation Algorithm}

The Fuzzy Cost deviation algorithm produces a solution which may be nearer to optimal solution. Here we using the fuzzy cost and apply fever pivots on it to find the problems optimal solution.

In the Fuzzy Cost deviation algorithm, the row and column deviation of a cell for each row and column is computed as an ordered pair. The ordered pair is equal to the fuzzy transportation cost of the cell minus the minimum of the corresponding row or column fuzzy transportation cost. The ordered pair $(\varphi, \theta)$ is said to be the cost deviation of a cell where $\varphi$ is the row cost deviation and $\theta$ is the column cost deviation of the cell. The row and column with the largest cost deviation is found. Then, the minimum cost deviation vector for the corresponding row and column is also found and then follow the algorithm.

The Procedure for solving fuzzy transportation problem using fuzzy cost deviation algorithm is given below:

Step1: The fuzzy cost deviation table is constructed for the converted fuzzy transportation problem.

Step 2: A row r, which contains the maximum fuzzy row cost deviation is found as $(a, b)$.

Step 3: A column t, which contains the maximum fuzzy column cost deviation is found as $(\mathrm{c}, \mathrm{d})$.

Step 4: The minimum fuzzy cost deviation in the rth row is found, say $(\mathrm{x}, \mathrm{y})($ Cell address).

Step 5: The minimum fuzzy cost deviation in the tth column is found, say $(\alpha, \beta)$ (Cell address).

Step 6: (a) If $x \neq \alpha$ and $y \neq \beta$, check the Row deviation (a,c) and column deviation $(\mathrm{b}, \mathrm{d})$ and allocate the maximum possible to the cell which deviation is maximum row or column. 
(b) If $x=\alpha$ and $y=\beta$, both cells $(\mathrm{x}, \mathrm{y})$ and $(\alpha, \beta)$ are same so allocate the maximum possible to them.

(c) If $x \neq \alpha$ and $y=\beta$ or $x=\alpha$ and $y \neq \beta$, check the Row deviation (a,c) and column deviation (b,d) and allocate the maximum possible to the cell which deviation is maximum row or column.

Step 8: The fuzzy transportation table is refined after deleting fully used fuzzy supply points and fully received fuzzy demand points. Incomplete used fuzzy supply points and incompletely received fuzzy demand points are modified.

Step 9: The fuzzy cost deviation table is constructed for the reduced fuzzy transportation problem. Then step 2 is executed.

Step 10: The above process is repeated until all fuzzy supply points are fullyused or allfuzzy demand points are fully received.

Step 11: A fuzzy solutions is resulted for the problem from the allotment.

\section{Numerical Example}

Widgetco manufactures widgets at two factories, one in Memphis and one in Denver. The Memphis factory can produce approximately as $(100,150,200)$ widgets per day, and the Denver factory can produce approximately as $(150,200,250)$ widgets per day. Widgets are shipped by air to customers in Los Angeles and Boston. The customers in each city require $(100,130,160)$ widgets per day. Because of the deregulation of airfares, Widgetco believes that it may be cheaper to first fly some widgets to New York or Chicago and then fly them to their final destinations. The costs of flying a widget are shown in Table. Widgetco wants to minimize the total cost of shipping the required widgets to its customers.

\begin{tabular}{|c|c|c|c|c|c|c|}
\hline & \multicolumn{7}{|c|}{ To } \\
\hline From & Memphis & Denver & NewYork & Chicago & L.A. & Boston \\
\hline Memphis & $(0,0,0)$ & - & $(7,8,9)$ & $(12,13,14)$ & $(24,25,26)$ & $(27,28,29)$ \\
\hline Denver & - & $(0,0,0)$ & $(14,15,16)$ & $(11,12,13)$ & $(25,26,27)$ & $(24,25,26)$ \\
\hline New York & - & - & $(0,0,0)$ & $(5,6,7)$ & $(15,16,17)$ & $(16,17,18)$ \\
\hline Chicago & - & - & $(5,6,7)$ & $(0,0,0)$ & $(13,14,15)$ & $(15,16,17)$ \\
\hline L.A. & - & - & - & - & $(0,0,0)$ & - \\
\hline Boston & - & - & - & - & - & $(0,0,0)$ \\
\hline
\end{tabular}

Solution. In this problem, Memphis and Denver are supply points, with supplies of $(100,150,200)$ and $(150,200,250)$ widgets per day, respectively. New York and Chicago are transshipment points. Los Angeles and Boston are demand points, each with a demand of $(100,130,160)$ widgets per day. A graphical representation of possible shipments is given in Figure. 
For the Widgetco example, this procedure yields the transportation tableau. Because $\mathrm{T}=($ total supply $)=(100,150,200)+(150,200,250)=(250,350,450)$ and $($ total demand $)=(100,130,160)+(100,130,160)=(200,260,320)$ the dummy demand point has a demand of $(250,350,450)-(200,260,320)=(-70,90,250)$ (which is equal to $(50,90,130)$ ). The other supplies and demands in the transportation tableau are obtained by adding $\mathrm{T}=(250,350,450)$ to each transshipment point's supply and demand.

The Fuzzy transportation table converted from Fuzzy transshipment table

\begin{tabular}{|c|c|c|c|c|c|c|}
\hline & \multicolumn{7}{|c|}{ To } \\
\hline From & NewYork & Chicago & L.A. & Boston & Dummy city & \\
\hline Memphis & $(7,8,9)$ & $(12,13,14)$ & $(24,25,26)$ & $(27,28,29)$ & $(0,0,0)$ & $(100,150,200)$ \\
\hline Denver & $(14,15,16)$ & $(11,12,13)$ & $(25,26,27)$ & $(24,25,26)$ & $(0,0,0)$ & $(150,200,250)$ \\
\hline New York & $(0,0,0)$ & $(5,6,7)$ & $(15,16,17)$ & $(16,17,18)$ & $(0,0,0)$ & $(250,350,450)$ \\
\hline Chicago & $(5,6,7)$ & $(0,0,0)$ & $(13,14,15)$ & $(15,16,17)$ & $(0,0,0)$ & $(250,350,450)$ \\
\hline & $(250,350,450)$ & $(250,350,450)$ & $(100,130,160)$ & $(100,130,160)$ & $(50,90,130)$ & \\
\hline
\end{tabular}

The fuzzy cost deviation table is below

\begin{tabular}{|c|c|c|c|c|c|}
\hline & \multicolumn{5}{|c|}{ To } \\
\hline From & NewYork & Chicago & L.A. & Boston & Dummy city \\
\hline Memphis & $((7,8,9)$, & $((12,13,14)$, & $((24,25,26)$, & $((27,28,29)$, & $((0,0,0)$, \\
& $(7,8,9))$ & $(12,13,14))$ & $(9,11,13))$ & $(10,12,14))$ & $(0,0,0))$ \\
\hline Denver & $((14,15,16)$, & $((11,12,13)$, & $((25,26,27)$, & $((24,25,26)$, & $((0,0,0)$, \\
& $(14,15,16))$ & $(11,12,13))$ & $(10,12,14))$ & $(7,9,11))$ & $(0,0,0))$ \\
\hline New York & $((0,0,0)$, & $((5,6,7)$, & $((15,16,17)$, & $((16,17,18)$, & $((0,0,0)$, \\
& $(0,0,0))$ & $(5,6,7))$ & $(0,2,4))$ & $(-1,1,3))$ & $(0,0,0))$ \\
\hline Chicago & $((5,6,7)$, & $((0,0,0)$, & $((13,14,15)$, & $((15,16,17)$, & $((0,0,0)$, \\
& $(5,6,7))$ & $(0,0,0))$ & $(-2,0,2))$ & $(-2,0,2))$ & $(0,0,0))$ \\
\hline
\end{tabular}

In the above fuzzy cost deviation table the Maximum Fuzzy number at the row in the cell is $(1,4)$ in that row the minimum Fuzzy number in the cell is $(1,5)$.

Then In the above fuzzy cost deviation table the Maximum Fuzzy number at the Column in the cell is $(2,1)$ in that Column the minimum Fuzzy number in the cell is $(3,1)$.

Therefore $1 \neq 3$ and $4 \neq 1$ so check the row and column deviation $((27,28,29)$, $(14,15,16))$ and $((10,12,14),(14,15,16))$, the row deviation is greater than column deviation.

So allocate the maximum to the cell $(1,5)$ in the row

\begin{tabular}{|c|c|c|c|c|c|c|}
\hline & \multicolumn{5}{|c|}{ To } \\
\hline From & NewYork & Chicago & L.A. & Boston & Dummy city & $(0,0,0)$ \\
\hline Memphis & $(7,8,9)$ & $(12,13,14)$ & $(24,25,26)$ & $(27,28,29)$ & $\begin{array}{c}(100,150,200) \\
(-30,60,150)\end{array}$ \\
\hline Denver & $(14,15,16)$ & $(11,12,13)$ & $(25,26,27)$ & $(24,25,26)$ & $(0,0,0)$ & $(150,200,250)$ \\
\hline New York & $(0,0,0)$ & $(5,6,7)$ & $(15,16,17)$ & $(16,17,18)$ & $(0,0,0)$ & $(250,350,450)$ \\
\hline Chicago & $(5,6,7)$ & $(0,0,0)$ & $(13,14,15)$ & $(15,16,17)$ & $(0,0,0)$ & $(250,350,450)$ \\
\hline & $(250,350,450)$ & $(250,350,450)$ & $(100,130,160)$ & $(100,130,160)$ & $(50,90,130)$ & \\
\hline
\end{tabular}

After Allocation the remaining table is 


\begin{tabular}{|c|c|c|c|c|c|}
\hline & \multicolumn{5}{|c|}{ To } \\
\hline From & NewYork & Chicago & L.A. & Boston & \\
\hline Memphis & $(7,8,9)$ & $(12,13,14)$ & $(24,25,26)$ & $(27,28,29)$ & $(-30,60,150)$ \\
\hline Denver & $(14,15,16)$ & $(11,12,13)$ & $(25,26,27)$ & $(24,25,26)$ & $(150,200,250)$ \\
\hline New York & $(0,0,0)$ & $(5,6,7)$ & $(15,16,17)$ & $(16,17,18)$ & $(250,350,450)$ \\
\hline Chicago & $(5,6,7)$ & $(0,0,0)$ & $(13,14,15)$ & $(15,16,17)$ & $(250,350,450)$ \\
\hline & $(250,350,450)$ & $(250,350,450)$ & $(100,130,160)$ & $(100,130,160)$ & \\
\hline
\end{tabular}

Now the Fuzzy cost deviation table for the above problem is

\begin{tabular}{|c|c|c|c|c|}
\hline & \multicolumn{4}{|c|}{ To } \\
\hline From & NewYork & Chicago & L.A. & Boston \\
\hline Memphis & $((-2,02)$, & $((3,5,7)$, & $((15,17,19)$, & $((18,20,22)$, \\
& $(7,8,9))$ & $(12,13,14))$ & $(9,11,13))$ & $(10,12,14))$ \\
\hline Denver & $((1,3,5)$, & $((-2,0,2)$, & $((12,14,16)$, & $((11,13,15)$, \\
& $(14,15,16))$ & $(11,12,13))$ & $(10,12,14))$ & $(7,9,11))$ \\
\hline New York & $((0,0,0)$, & $((5,6,7)$, & $((15,16,17)$, & $((16,17,18)$, \\
& $(0,0,0))$ & $(5,6,7))$ & $(0,2,4))$ & $(-1,1,3))$ \\
\hline Chicago & $((5,6,7)$, & $((0,0,0)$, & $((13,14,15)$, & $((15,16,17)$, \\
& $(5,6,7))$ & $(0,0,0))$ & $(-2,0,2))$ & $(-2,0,2))$ \\
\hline
\end{tabular}

In the above fuzzy cost deviation table the Maximum Fuzzy number at the row in the cell is $(1,4)$ in that row the minimum Fuzzy number in the cell is $(1,1)$.

Then In the above fuzzy cost deviation table the Maximum Fuzzy number at the Column in the cell is $(2,1)$ in that Column the minimum Fuzzy number in the cell is $(3,1)$.

Therefore $1 \neq 3$ and $1=1$ so check the row and column deviation $((18,20,22)$, $(1,3,5))$ and $((10,12,14),(14,15,16))$, the Row deviation is greater than column deviation.

So allocate the maximum to the cell $(1,1)$ in the row

\begin{tabular}{|c|c|c|c|c|c|}
\hline & \multicolumn{5}{|c|}{ To } \\
\hline From & NewYork & Chicago & L.A. & Boston & \\
\hline Memphis & $(7,8,9)$ & $(12,13,14)$ & $(24,25,26)$ & $(27,28,29)$ & $(-30,60,150)$ \\
& $(-30,60,150)$ & & & & \\
\hline Denver & $(14,15,16)$ & $(11,12,13)$ & $(25,26,27)$ & $(24,25,26)$ & $(150,200,250)$ \\
\hline New York & $(0,0,0)$ & $(5,6,7)$ & $(15,16,17)$ & $(16,17,18)$ & $(250,350,450)$ \\
\hline Chicago & $(5,6,7)$ & $(0,0,0)$ & $(13,14,15)$ & $(15,16,17)$ & $(250,350,450)$ \\
\hline & $(250,350,450)$ & $(250,350,450)$ & $(100,130,160)$ & $(100,130,160)$ & \\
& $(100,290,480)$ & & & & \\
\hline
\end{tabular}

Similarly continue the algorithm we get the final allocation table is given below

\begin{tabular}{|c|c|c|c|c|c|c|}
\hline & \multicolumn{6}{|c|}{ To } \\
\hline From & NewYork & Chicago & L.A. & Boston & Dummy city & \\
\hline Memphis & $\begin{array}{c}(7,8,9) \\
(-\mathbf{3 0}, \mathbf{6 0 , 1 5 0 )}\end{array}$ & $(12,13,14)$ & $(24,25,26)$ & $(27,28,29)$ & $\begin{array}{c}(0,0,0) \\
(50,90,130)\end{array}$ & $\begin{array}{c}(100,150,200) \\
(-30,60,150)\end{array}$ \\
\hline Denver & $(14,15,16)$ & $(11,12,13)$ & $\begin{array}{c}(25,26,27) \\
(\mathbf{- 2 5 0 , 7 0 , 3 9 0 )}\end{array}$ & $\begin{array}{c}(24,25,26) \\
(\mathbf{1 0 0 , 1 3 0 , 1 6 0 )}\end{array}$ & $(0,0,0)$ & $(150,200,250)$ \\
\hline New York & $\begin{array}{c}(0,0,0) \\
(\mathbf{1 0 0 , 2 9 0 , 4 8 0 )}\end{array}$ & $(5,6,7)$ & $\begin{array}{c}(15,16,17) \\
(-230,60,350)\end{array}$ & $(16,17,18)$ & $(0,0,0)$ & $\begin{array}{l}(250,350,450) \\
(-230,60,350)\end{array}$ \\
\hline Chicago & $(5,6,7)$ & $\begin{array}{c}(0,0,0) \\
(\mathbf{2 5 0}, \mathbf{3 5 0}, \mathbf{4 5 0})\end{array}$ & $(13,14,15)$ & $(15,16,17)$ & $(0,0,0)$ & $(250,350,450)$ \\
\hline & $\begin{array}{l}(250,350,450) \\
(100,290,480)\end{array}$ & $(250,350,450)$ & $\begin{array}{c}(100,130,160) \\
(-250,70,390)\end{array}$ & $(100,130,160)$ & $(50,90,130)$ & \\
\hline
\end{tabular}


Therefore the allocations are:

1. Memphis to New York is $(\mathbf{- 3 0 , 6 0 , ~ 1 5 0 )}$ quantities.

2. New York to Los Angles is $(\mathbf{- 2 3 0 , 6 0 , 3 5 0 )}$ quantities.

3. Denver to Los Angles is $(\mathbf{- 2 5 0 , 7 0 , 3 9 0 )}$ quantities.

4. Denver to Boston is $(\mathbf{1 0 0 , 1 3 0 , 1 6 0 )}$ quantities.

The rim requirements at Los Angles and Boston are fulfilled with minimum cost.

\section{Conclusion}

In this paper, the transshipment with transit point is taken as a main theme. This transit points never required any demand or supply but this is act as a origin and also supply after the problem is converted to transportation. Also in this type, the extra buffer at the origin and demand are reduced.

\section{References}

[1] Bellman, R.E., Zadeh, L.A., Decision making in a fuzzy environment, Management Science, 17 (1970).

[2] Kaufmann, A., Introduction to the theory of fuzzy sets, Vol.1 (Academic Press, New York, 1976).

[3] Nagoor Gani, A., and Abdul Razak, K., Solving Transportation Problem using Fuzzy Number, Bulletin of pure and applied science, 23E(2) (2004), 281-289.

[4] Nagoor Gani,A., Baskaran. R. and Mohamed Assarudeen. S.N., Transshipment Problem in Fuzzy Environment, Int. J. of Math. Sci. \& Engg. Appls., Vol. 5 No. III, 2011, pp. $57-74$.

[5] Orden. A, Management Sci. 2 (1956) 276-85.

[6] Ramakrishnan. G. S., An improvement to Goyal's modified VAM for the unbalanced transportation problem, Journal of Operational Research Society 39(6), 609-610, 1988.

[7] Shimshak. D. G., Kaslik, J. A. and Barclay, T. D., A modification of Vogel's approximation method through the use of heuristics, Infor 19, 259-263, 1981.

[8] Shore. H.H., The Transportation Problem and the Vogel Approximation Method, Decision Sciences (3-4),441-457, 1970.

[9] Zadeh, L.A., Fuzzy sets, Information Control, 8 (1965), 338-353. 